\title{
A escola como uma organização educativa: uma análise a partir do intelectual Anísio Teixeira
}

\section{The school as an educational organization: an analysis from the intellectual Anísio Teixeira}

\author{
Eliane da Conceição Matta ${ }^{1}$, Pablo Silva Machado Bispo dos Santos ${ }^{1}$
}

\section{RESUMO}

O estudo ora apresentado visa compreender a escola como uma organização educativa à luz do pensamento de Anísio Teixeira. Assim sendo, primeiramente é importante ressaltar o seu pensamento em relação à sociedade e a escola. Anísio Teixeira marcou a educação brasileira com uma visão de sociedade e arcabouço teórico-prático à frente de sua época. Um intelectual da educação que contribuiu para a proposta de um sistema educacional que tivesse ênfase no desenvolvimento do intelecto e da formação humana do indivíduo na sociedade. Além disso, defendia o ensino público, gratuito, laico e obrigatório. Ocupou diferentes cargos públicos na educação a partir dos anos de 1920, o que possibilitou uma mudança no pensamento educacional brasileiro da época. $\mathrm{O}$ artigo traz uma reflexão acerca de como Anísio Teixeira entendia a educação e a função da escola na sociedade.

Palavras-chave: Administração Educacional; Escola; Sociedade.

\section{ABSTRACT}

The study presented here aims to understand the school as an educational organization in the light of Anísio Teixeira's thinking. Therefore, first it is important to emphasize his thinking in relation to society and school. Anísio Teixeira marked Brazilian education with a vision of society and a theoretical-practical framework ahead of its time. An educational intellectual who contributed to the proposal of an educational system that emphasized the development of the intellect and the human formation of the individual in society. In addition, he defended public, free, secular and compulsory education. He held different public positions in education from the 1920s onwards, which enabled a change in Brazilian educational thinking at the time. The article reflects on how Anísio Teixeira understood education and the role of schools in society.

Keywords: Educational Administration; School; Society.

\footnotetext{
${ }^{1}$ Mestre em Educação pelo PPGEDU/UFF. Doutoranda em Educação pelo PPGEDU/UFF. Pesquisadora integrante dos Núcleos de Pesquisa POLIS, Universidade Federal Fluminense. elianedamatta@gmail.com 1 Prof. Associado II. Universidade Federal Fluminense, Faculdade de Educação/ Departamento SSE e PPGEDU/UFF. Líder do Núcleo de Pesquisa POLIS/UFF.
} 


\title{
INTRODUÇÃO
}

Anísio Spínola Teixeira nasceu em Caetité, sertão da Bahia no ano de 1900 e faleceu no ano de 1971 no Rio de Janeiro. Estudou no colégio jesuíta em sua cidade natal. Cursou Direito na Universidade do Rio de Janeiro e viajou pela Europa para observar os diferentes sistemas de ensino. No ano de 1927 viajou para os Estados Unidos na busca de conhecimentos sobre as ideias do filósofo John Dewey que se relacionavam à valorização da experimentação na educação.

A sociedade brasileira a partir da Revolução de 1930, com a ascensão do ideário liberal começa ter avanços em relação à ciência ${ }^{2}$, proporcionando a ideia de progresso, aplicada por Anísio, apreendida especialmente pela influência de John Dewey e Paul Kilpatrick. A partir dessa premissa, Anísio indica a necessidade de transformação da escola:

\begin{abstract}
Há, antes de tudo, uma transformação radical com a criação da escola comum para todos, em que a criança de todas as posições sociais iria formar a sua inteligência, a sua vontade e o seu caráter, os hábitos de pensar, de agir e de conviver socialmente. Essa escola formava a inteligência, mas não formava o intelectual. $\mathrm{O}$ intelectual seria das especialidades de que a educação posterior iria cuidar, mas não constitui objeto dessa escola de formação comum a ser, então, inaugurada. Por outro lado, além dessa total inovação, que representava essa escola para todos, a própria educação tradicional e ainda existente teria de se transformar, para atender à multiplicidade de vocações, ofícios e profissões em que a nascente sociedade liberal e progressista começou a desdobrar-se (TEIXEIRA, 1994, p.02)
\end{abstract}

A escola de acordo com Anísio Teixeira teria que se transformar de forma radical para uma educação comum, não nos modelos que se apresentava, mas de modo que atendesse às necessidades de uma nova sociedade que estava se constituindo, em um processo acelerado de urbanização e industrialização em um marco temporal que atravessa toda a década de 1930 e 1950, atingindo seu ápice após 1946. Essa foi uma das críticas à escola tradicional, que se apresentava de forma arcaica em relação às necessidades da sociedade liberal que estava emergindo. Isso proporcionou refletir sobre uma escola nova que segundo Teixeira (1968), é a tentativa de orientar a escola no sentido de um movimento iniciado na sociedade de revisão de velhos conceitos psicológicos e sociais.

Importante colocar as diversas críticas à escola tradicional, em virtude de não atender as demandas de uma sociedade em transformação. O conhecimento intelectual não tinha proximidade com o conhecimento prático na escola. No sistema de conhecimento científico

2 Anísio Teixeira defendia a ideia de que a educação possuía um status científico que a situa como ciência aplicada, ou, arte-ciência. TEIXEIRA, Anísio. Ciência e arte de educar. Educação e Ciências Sociais. v.2, n.5, 1957. p.5-22. 
moderno os dois tipos de conhecimento, o científico e o empírico, apresentam ligação com a realidade concreta. Daí a necessidade da experimentação, da comprovação, da realidade empírica.

\begin{abstract}
Porque desse encontro entre o "intelecto" e a oficina é que partiu todo o sistema de conhecimento científico moderno, que nada mais é que o conhecimento racional tornado fértil e fecundo, pela sua ligação com a realidade concreta do mundo e da existência. Toda uma nova filosofia do conhecimento se estabeleceu em oposição à formula grega de dualismo entre o racional e o empírico. Efetivamente, as diferenças entre o experimental e o empírico passaram a ser antes de precisão de métodos, segurança de observação e de controle na verificação, do que de objeto ou de natureza. Na realidade, a diferença passou a ser antes de grau de segurança no conhecimento do que da natureza do conhecimento. (TEIXEIRA, 1994, p.03)
\end{abstract}

A escola tradicional, que de acordo com Saviani (2012), era uma escola organizada e centrada no professor na transmissão dos conhecimentos aos alunos, motivou críticas no que se refere à formação e preparo. Teixeira coloca que homens racionais ou escolásticos eram voltados às atividades intelectuais, para o trabalho científico e não empírico. Como a sociedade estava em plena transformação, havia a necessidade de preparar o homem para pesquisa, o ensino e a tecnologia, tendo uma base comum, sendo que cada um se dedicaria a um conhecimento científico específico.

As escolas não foram criadas para a renovação da sociedade, mas sim para perpetuar um determinado modelo e estrutura social. No caso a escola tradicional não era destinada a uma formação comum que pudesse romper com o dualismo existente na sociedade. A escola reforçava a posição de cada indivíduo na sociedade, e não conseguia avançar no sentido de proporcionar uma educação onde todos os indivíduos pudessem ter uma formação para uma atuação na sociedade.

Anísio Teixeira trouxe contribuições acerca da organização da escola para o seu tempo, como por exemplo, a necessidade da escola integral para as crianças desfavorecidas de ambiente cultural, com limitações e carências em virtude de sua situação de classe, a proposta dos parques escolares. Em função da extensão territorial do Brasil traz à tona a necessidade da descentralização, na busca por uma educação democrática com vistas a uma administração, com um programa de responsabilidade local, mas aconselhada tecnicamente pelos entes estadual e federal. Essa reflexão possibilita compreender a educação como algo que precisa atender as necessidades de um determinado local, não sendo um programa educativo imposto, sem sentido e sem significado para o indivíduo.

Seguindo essa linha de raciocínio entendemos que a educação escolar não pode ser uma imposição de outra cultura, precisa ser organizada a partir de sua cultura escolar e identidade cultural local, para que possa atender as necessidades de uma determinada comunidade escolar. Anísio já trazia uma nova reflexão, um novo entendimento em relação à educação: a escola nova. transformada, como se transformam todas as instituições humanas, à medida 
que lhes podemos aplicar conhecimentos mais preciosos dos fins e meios a que se destinam. (TEIXEIRA, 1967, p.25-26)

A escola precisava se reinventar e o movimento da Escola Nova, cujas ideias exprimiam principalmente no Manifesto dos Pioneiros da Educação Nova ${ }^{3}$, um viés transformador, inovador, pois a transformação da sociedade era algo real. Essa transformação nos seus aspectos econômicos e sociais ocorreu a partir do desenvolvimento da ciência, o que suscita urgência na transformação da escola, no sentido de estar alinhada às mudanças da sociedade.

A ampliação da ciência é fruto da invenção das máquinas, onde o homem faz uso da ciência experimental, o que permitiu o crescimento das cidades e consequentemente o aumento da civilização. Com isso, a ciência trouxe uma nova mentalidade, determinando uma nova ordem das coisas, através de uma perspectiva de mudança e transformação, ou seja, nada é estável, tudo passa a ser considerado dinâmico. Com a experimentação científica vem o progresso como algo expansivo e ilimitado. A ciência experimental coloca em cheque a ordem social e moral vistas como verdades absolutas. Através da construção de uma nova civilização, algumas mudanças começam a ocorrer em diferentes aspectos, tais como: costumes, hábitos, organização familiar, entre outros.

Com isso, Teixeira (1967) coloca que a nova ordem de mudança constante altera o conceito da escola tradicional, pois a nova escola precisa preparar o homem para resolver e indagar por si os seus problemas, assim como construir uma escola para um futuro imprevisível, em função de uma civilização em constante transformação. Todas essas mudanças trazem consigo ao mundo contemporâneo a tendência democrática: "Democracia é, essencialmente, o modo de vida social em que cada indivíduo conta como uma pessoa". (TEIXEIRA, 1967, p.35)

As novas tendências da civilização atuam na escola proporcionando a sua transformação para atender a sociedade moderna que estava se constituindo. As novas tendências da civilização promovem o desapego de velhos modelos de sistemas autoritários tradicionais que regulavam a sociedade. Sendo assim, a noção de liberdade é considerada no novo modelo de civilização.

De acordo com Teixeira (1967) a escola tradicional estava prestes a desaparecer, pois representava uma sociedade diferente da que estava sendo construída. Sendo assim, a escola é a representação da sociedade a que serve. Com isso, a escola passa a ter novas responsabilidades:

Que enormes, pois, são as novas responsabilidades da escola: educar em vez de instruir; formar homens livres em vez de homens dóceis; preparar para um futuro incerto e desconhecido em vez de transmitir um passado fixo e claro; ensinar a viver com mais inteligência, com mais tolerância, mais finamente, mais nobremente e com maior felicidade, em vez de simplesmente ensinar dois

\footnotetext{
${ }^{3}$ Foi um movimento organizado por uma elite intelectual brasileira, como Anísio Teixeira e Fernando de Azevedo, no ano de 1932. Idealizava uma renovação educacional no país, diante da desorganização do sistema educacional da época. Uma das propostas era que o Estado organizasse um plano de educação que priorizasse uma escola única, laica, obrigatória e gratuita.
} 
ou três instrumentos de cultura e alguns manuaizinhos escolares.... (TEIXEIRA, 1967, p.41)

A escola diante da nova civilização passa a assumir uma nova responsabilidade. Para a consolidação torna-se necessário pensar a escola para uma nova finalidade da educação, com uma nova organização, um novo programa, um novo método.

\section{ESCOLA E SOCIEDADE NA PESPECTIVA PRAGMÁTICA DE ANÍSIO TEIXEIRA}

A escola sendo reinventada para servir um novo modelo de sociedade, altera a psicologia da escola tradicional, onde o ato de aprender ganhou novo significado. O aprender esteve durante muitos anos associado à memorização de conteúdos que eram transmitidos pelos adultos. Com o passar dos anos, há a exigência de se compreender o que estava sendo decorado. Várias formas de decorar foram utilizadas como modo de aprendizado para os alunos.

A nova psicologia traz que aprender significa muito mais do que decorar algo. Aprender está associado à aquisição de uma determinada habilidade, a assimilação de algo para uma possível ação. $\mathrm{O}$ ato de aprender é um processo ativo que está relacionado à prática. Sendo assim, a escola precisa se organizar de forma diferente:

\footnotetext{
Logo, se a escola quer ter a função integral de educação, deve organizar-se de sorte que a criança encontre aí um ambiente social em que viva plenamente. A escola não pode ser uma simples classe de exercícios intelectuais especializados. (TEIXEIRA, 1967, p. 45)
}

Com as mudanças ocorridas na sociedade através da ciência, uma nova lógica de compreensão do ato de aprender emerge. Estudos relacionados à nova psicologia impulsionam a reflexão sobre o ato de aprender relacionado à prática. Condicionado a isso, a escola necessita rever a sua organização de modo a proporcionar uma aprendizagem em consonância com a prática, para que o aluno tenha a oportunidade de interagir, vivenciar através da experiência. Novas concepções de aprendizagem são colocadas frente à organização escolar. Isso traz à tona a função da escola diante da sociedade que estava sendo constituída.

Um novo olhar sobre a educação se constituía com o pensamento de Teixeira (1967). Ele coloca que a escola Progressista possibilita uma reconstrução permanente da vida, com maior liberdade, tendo como base um ambiente em transformação que começou a surgir a partir da era industrial. A partir dos ideais escolanovistas, a pedagogia desenvolvida na Escola Progressiva (que teve como mais conhecido exemplo a Escola Parque) ocorre um movimento de reorganização do objetivo principal da escola. Assim, a criança se torna o centro de toda atividade escolar, não sendo mais o adulto. O que importa é organizar a escola de modo que atenda aos interesses, necessidades e direitos da criança. A criança começa a ser entendida a partir de suas 
diferenças, e a educação na escola é um ato de crescimento para a vida futura, o que provocou uma revisão do próprio conceito de educação.

Educar é crescer. E crescer é viver. Educação é, assim, vida no sentido mais autentico da palavra. Alargada, desse modo, na sua compreensão, não a podemos encontrar nos processos mecânicos da escola tradicional. Como aí encontrar o móvel centralizador e harmonizador do crescimento ou da educação da criança, se não há a sua participação, nem seu desejo, nem a sua atenção, e se a obra interna da educação de nada disso pode prescindir? (TEIXEIRA, 1967, p.57)

Conforme dito anteriormente, a criança se torna o centro principal da escola. Com isso, a escola necessita se organizar para o atendimento da criança em suas diferentes especificidades. Considerar a criança e seu processo de desenvolvimento, a sua liberdade, os interesses, as suas necessidades, dá um novo sentido à escola. A escola começa a transitar para uma concepção de educação que não era considerada pela escola tradicional. No modelo escolar no qual havia a valorização de métodos mecânicos de aprendizagem, não eram consideradas as diferenças, individualidades das crianças. Além disso, a criança não era considerada o eixo principal da escola.

A partir do pressuposto de que a criança é o centro principal da escola, a educação ganha novo sentido dentro desse contexto. A escola é introduzida como parte da vida da criança, considerando as experiências construídas dentro e fora da escola. A escola sai do papel de simples transmissora de conhecimentos para uma nova tarefa de acompanhamento do desenvolvimento da criança. E com isso, um novo conceito sobre o ato de aprender é construído:

\footnotetext{
Aprender não significa somente fixar na memória, nem dar expressão verbal e própria ao que se fixou na memória. Desde que a escola e a vida não mais se distinguem, aprender importará sempre em uma modificação da conduta humana, na aquisição de alguma coisa que reaja sobre a vida e, de algum modo, lhe enriqueça e aperfeiçoe o sentido. (TEIXEIRA, 1967, p.60)
}

$\mathrm{Na}$ escola o ato de aprender ganha outra configuração, começa ter um novo sentido, significado. Com isso, o planejamento se torna algo diferenciado ao que acontecia na escola tradicional. Essa nova configuração proporcionou refletir sobre os programas escolares oferecidos, bem como o planejamento pedagógico administrativo.

\section{Administração e Planejamento Educacional para Anísio Teixeira}

De acordo com Teixeira (1967), o programa escolar deverá ser planejado e aceito pelo aluno, com atividades que proporcione a aprendizagem de conhecimentos indispensáveis para a resolução de problemas de sua própria vida. $\mathrm{O}$ ato de aprender precisa estar ligado às experiências de vida da criança, promovendo a resolução de problemas que serão vivenciados ao longo da vida. 
A escola tendo em vista que a criança é o centro de sua ação, necessita se reinventar ressignificando o seu papel e construindo novos conceitos no que tange ao processo de aprendizagem, aos programas escolares, ao planejamento, a organização da escola como um todo. Refletir sobre essa organização escolar é colocar em discussão a concepção de educação e o modelo de escola a ser construído na sociedade. Teixeira (1967) traz essa discussão com riqueza de detalhes, o que possibilita dizer que a escola ganhou um novo significado a partir de suas reflexões acerca do seu sentido para uma sociedade que estava em processo de transformação. A escola não poderia ser a mesma, não priorizando a experiência, a individualidade, a liberdade, a vida. Assim de acordo com o autor:

Sendo a educação o processo de contínua reorganização e reconstrução da experiência, é um processo individual e pessoal, antes de ser social. Pelo menos em sua fase de plena consciência, o caráter individual e pessoal se acentua particularmente. (TEIXEIRA, 1967, p. 91)

Teixeira (1985) coloca que a reorganização escolar começa a ter como base estudos psicológicos e filosóficos o que trouxeram à tona a reflexão sobre a formação livre do indivíduo. Os estudos do autor mostram a valorização do indivíduo no processo educacional. A individualidade do homem é adquirida à medida que ele é capaz de fazer reflexão a partir da construção de sua própria experiência. A reflexão do autor possibilita compreender a educação a partir de novas concepções que foram sendo construídas com base em um pensamento liberal que emergia com o objetivo de promover a reconstrução da sociedade.

\section{Anísio Teixeira, Escola e Democracia}

Quando Anísio problematiza como a sociedade poderia ser mais democrática, o autor reconhece a divisão das classes sociais e coloca a escola como um local onde haveria a possibilidade de construção das relações democráticas, propiciando a equalização social. A divisão de classe a que o autor se refere está relacionada à organização do sistema escolar que dividia as atividades em manuais e intelectuais. Essa divisão não poderia existir de acordo com o autor, pois não proporciona ao indivíduo sua construção integral em uma sociedade democrática.

A função da escola seria de ampliação de oportunidades a todos os níveis sociais, possibilitando mais igualdade, minimizando as diferenças e as desigualdades existentes na sociedade. Anísio Teixeira mostrava um entusiasmo pela educação o que foi considerado "otimismo pedagógico". Uma preocupação não somente com o analfabetismo, mas também com a difusão da escola integral, além da formação profissional e cultural que propicia o progresso da população brasileira.

Sobre a escola integral: 
Tenta justificar em seus escritos a necessidade da escola integral, sobretudo para as crianças desfavorecidas que, além de todas as limitações e carências decorrentes da sua situação de classe, não contam com um ambiente cultural mínimo que lhes possibilite acolher o que é transmitido na escola. (TEIXEIRA, 1985, p.50)

Com isso, é possível considerar que o autor reflete a escola como um espaço que ele mesmo coloca como de "recuperação social". A ideia é a construção de uma escola que cumpra o papel de equalizadora na sociedade, possibilitando a ascensão social e de oportunidades para todos. E ao referendar a escola com a função de civilizadora, enfatiza a necessidade de considerar a experiência da criança:

De certa forma a escola rejeita a experiência que a criança do povo traz à escola ao tentar substituir os seus "maus hábitos" por aqueles considerados “civilizados". Anísio considera que essa substituição é que caracteriza a função civilizadora da escola. Com isso ele pretende institucionalizar os menos favorecidos da linguagem, possibilitando a estes desfrutar dos bens que o mundo moderno oferece. Negar-lhes a educação integral seria aliená-los do programa seria uma injustiça social. (TEIXEIRA, 1985, p.51).

A educação integral seria uma educação pautada na ampliação das tarefas sociais e culturais. Tem como base a elevação cultural das classes populares nos seus diferentes aspectos, físicos e intelectuais na formação do indivíduo. A educação integral propicia a formação integral do indivíduo. Com isso, a necessidade de ampliação das funções da escola, que não poderia estar organizada de acordo com o modelo da escola tradicional.

O Manifesto dos Pioneiros da Educação (1932), citado inicialmente no artigo, foi um documento com uma proposta de renovação educacional para o país. Nesse documento a ideia de uma educação integral estava presente no sentido de ser um direito do indivíduo, com vistas a uma educação pública que proporcionasse o desenvolvimento de diferentes dimensões para a sua formação.

Sendo assim, a compreensão de uma educação integral é a superação da ideia de alfabetização que era defendida na ocasião. A educação integral era algo para além da alfabetização, uma educação que possibilitasse a ampliação da cultura, promovesse a equalização de oportunidades nas classes populares. Com isso a escola deixa de ser destinada somente à elite e passa ser um espaço onde será oferecida uma educação comum ou pública ligada ao trabalho, à prática e à ciência a todas as classes sociais.

A proposta de Anísio é inovadora para os anos de 1930-1950, pois enfatiza a necessidade de reformulação do espaço educativo. Para que haja um trabalho educacional de qualidade são necessárias instalações adequadas, espaços que promovam a aprendizagem dos alunos.

Anísio pensou nas escolas de classe e nas escolas parque. As escolas de classe ou nucleares tinham como meta, o ensino baseado em um programa comum e nas escolas parque 
receberia uma formação ligada a uma educação musical, física, sanitária, ou seja, uma formação para a atuação na sociedade. $\mathrm{O}$ aluno passaria dois turnos na escola, primeiro frequentaria a escola de classe ou nucleares e depois a escola parque.

\begin{abstract}
Haverá escolas nucleares e parques escolares, sendo obrigada a criança a frequentar regularmente as duas instalações. O sistema escolar para isso funcionará em dois turnos, para cada criança. Em dois turnos para crianças diversas de há muito vem funcionando. Daqui por diante será diferente: no primeiro turno a criança receberá em prédio adequado e econômico, o ensino propriamente dito; no segundo receberá em um parque-escola aparelhado e desenvolvido, a sua educação propriamente social, a educação física, a educação musical, a educação sanitária, a assistência alimentar e o uso da leitura em bibliotecas infantis e juvenis. (TEIXEIRA, 1997, p. 243, apud CAVALIERI, 2010, p. 256)
\end{abstract}

\title{
CONSIDERAÇÕES FINAIS
}

No que tange à atuação política, Anísio assumiu cargos importantes no cenário da educação brasileira. Em 1924 foi nomeado Inspetor Geral de Ensino na Bahia. No ano de 1931 assumiu a Diretoria Geral de Instrução Pública do Distrito Federal. No ano de 1952 é nomeado diretor do INEP, Instituto Nacional de Estudos Pedagógicos. Em 1961 participou da discussão da Lei de Diretrizes e Bases da Educação e do Plano Nacional de Educação no ano seguinte, entre outros cargos.

Anísio nos diversos períodos em que esteve à frente de cargos importantes na educação brasileira, proporcionou diferentes discussões e debates acerca da concepção de educação e da escola brasileira. Durante sua administração em diferentes espaços foi possível compreender que Anísio tinha um olhar para educação muito além do seu tempo. Com isso, ele consegue trazer para o debate a preocupação com a formação do professor, o planejamento na escola, a estrutura arquitetônica da escola entre outros.

Anísio em suas obras coloca a importância da igualdade de condições na dinâmica dos sistemas de ensino. Nesse sentido, todos deverão aprender elementos comuns relacionados à cultura para que possam interagir na sociedade. Sendo assim, a escola assume novas funções que antes não eram consideradas no âmbito educacional, como a reflexão sobre a política de equalização dos meios educacionais:

Assim, na nova política de equalização dos meios educacionais por ele proposta, a falha do aluno significa a falha da escola. Ela tem o dever de ensinar a todos, porque todos precisam dos elementos fundamentais da cultura para viver na sociedade moderna. O problema se inverte, o aluno reprovado significa fracasso da instituição, aparelho selecionador, encarregado do preparo fundamental dos cidadãos para a vida comum. Logo, a escola deve ser mudada para cumprir as novas funções. (TEIXEIRA, 1985, p.62) 
A questão do direito à educação é outro aspecto a ser colocado. De acordo com Teixeira (1985) a educação integral sendo um direito de cada indivíduo, deverá ser atribuição do Estado a sua organização para que se torne efetiva, tendo como base um plano geral da educação. A escola deverá ser acessível a todos na sociedade sem a distinção de estrutura social. Anísio se torna um defensor de que todos na sociedade têm o direito à educação. Além disso, coloca que para a superação das diferenças sociais, das crianças do povo, a escola precisa propiciar um ambiente semelhante ao das crianças ditas privilegiadas na sociedade.

Anísio também dá ênfase à liberdade. Como já foi explicitado no texto, Anísio coloca a criança como centro da escola, respeitando a personalidade infantil, tendo como base os estudos da psicologia que colocam a necessidade de uma formação livre espontânea para o desenvolvimento do indivíduo na sociedade, Teixeira (1985).

\begin{abstract}
A liberdade defendida por Anísio não é aquela do liberalismo inglês inicial, pregada como princípio da livre iniciativa econômica dos indivíduos ou liberdade universal de contrato. Coincide antes com a liberdade que significa a permissão para que cada indivíduo consiga para si o maior progresso possível e que isto tenha como consequência o maior progresso social. (TEIXEIRA, 1985, p.78)
\end{abstract}

Anísio enfatiza em suas propostas educativas a necessidade do valor da democracia. Faz uma reflexão sobre o posicionamento de um Estado Democrático, no sentido de tornar como tarefa a importância da liberdade para o desenvolvimento do progresso e da própria educação. A crítica de Anísio se dá ao governo que mantém a ideia de uma educação presa à história, em que a igreja dita às regras ao Estado de como funcionaria a educação. Defende a importância de uma escola gratuita, laica, pública, com liberdade, uma escola em que haja a igualdade de oportunidades para os indivíduos na sociedade.

Além disso, Anísio reflete sobre a escola tradicional que não possibilita a construção democrática:

\begin{abstract}
Acusando a escola tradicional como uma escola de privilégios, uma escola que sempre refletiu o dualismo social entre os "favorecidos" e os "desfavorecidos", Anísio afirma que ela nunca chegou a se caracterizar, ou ser de fato para todos, ela era para a chamada elite. Toda democracia de escola pública brasileira consistiu em permitir ao "pobre" uma educação pela qual pudesse participar da elite. (TEIXEIRA, 1985, p.87)
\end{abstract}

De acordo com Teixeira (1985) a nova sociedade democrática não poderia fazer distinção entre os indivíduos. A escola para ser democrática necessita ser comum a todos e também pública, sendo que todos os indivíduos deveriam ter o direito e o acesso à educação oferecida pelo Estado. Assim sendo, a escola assume um importante papel de educar para a construção de uma sociedade democrática em que todos os indivíduos reconheçam os direitos democráticos e o seu papel social. 
Anísio foi um intelectual que pensou na escola como a possibilidade da construção de uma educação transformadora. Priorizou a escola como um direito de todos, como a possibilidade de equalização na sociedade, como uma forma de colocar o aluno como o centro da educação, com liberdade para a construção da democracia.

Com essa pequena explanação de como Anísio refletia sobre a escola, a partir das diferentes experiências formativas que obteve ao longo de sua trajetória, como intelectual, filósofo, educador, administrador, é possível observar como seu pensamento foi sendo construído a partir de suas experiências e estudos sobre a educação. Nesse sentido, Anísio entende a escola como uma organização educativa e aponta diferentes aspectos que compõem esse novo olhar para essa nova organização escolar em oposição à escola tradicional.

Além disso, Anísio exerce uma liderança quando atua em diferentes cargos públicos na sociedade, o que proporciona a propagação de seus estudos, entendimentos, de sua filosofia, de seu pensamento sobre a educação brasileira. Nas obras de Anísio fica evidente a preocupação com a escola para todos os indivíduos e o desenvolvimento de suas potencialidades para a atuação na sociedade.

O estudo sobre o legado de Anísio Teixeira na educação brasileira foi possível constatar a sua defesa por uma educação como um direito, igualitária e democrática na sociedade. Referendando a história da educação brasileira, Anísio Teixeira foi um intelectual que trouxe a reflexão sobre a educação integral para uma sociedade que se encontrava em transformação com o advento da ciência e da tecnologia.

No entanto, o artigo proporciona o debate do pensamento de Anísio sobre a escola como uma organização educativa em diferentes aspectos, físicos, estruturais, filosóficos, pedagógicos, entre outros. Contudo, os estudos das obras de Anísio Teixeira são de extrema importância para o entendimento dos diferentes momentos da história da educação brasileira.

\section{REFERÊNCIAS}

CAVALIERI, Ana Maria. Anísio Teixeira e a educação integral. Paidéia. Maio-ago. 2010, vol. 20, no. 46, 249-259.

NUNES, Clarice. Anísio Teixeira / Clarice Nunes. Fundação Joaquim Nabuco. Recife: Editora Nassangana, 2010.

TEIXEIRA, Anísio. Ciência e arte de educar. Educação e Ciências Sociais. v.2, n.5, 1957. p.5-22.

TEIXEIRA, Anísio. Educação não é privilégio. $5^{\text {a }}$ ed. Rio de Janeiro: Editora UFRJ, 1994.

1996.

Educação é um direito. $2^{\mathrm{a}}$ edição. Rio de Janeiro: Editora UFRJ, 
Educação para a democracia: introdução à administração

educacional. $2^{a}$ edição. Rio de Janeiro: Editora UFRJ, 1997.

Pequena introdução à filosofia da educação: a escola

progressiva ou a transformação da escola. $5^{\mathrm{a}}$ edição. São Paulo: Editora Nacional, 1967.

TEIXEIRA, Mirene Mota Santos. O significado pedagógico da obra de Anísio Teixeira. São Paulo: Edições Loyola, 1985.

SAVIANI, Dermeval. Escola e democracia. 42 ed. Campinas, SP: Autores Associados, 2012. 